\title{
Portal Maya Kendaraan Kampung Berbasis IoT Dengan Sensor Ultrasonik
}

\author{
Moh.Saifudin Zufri ${ }^{1}$, Kunto Eko Susilo ${ }^{2}$ \\ Program Studi Sistem Komputer, Universitas Narotama \\ Jalan Arief Rachman Hakim 51, Surabaya, Indonesia \\ 1aifudin.zufri@gmail.com \\ ${ }^{2}$ kunto.eko.susilo@narotama.ac.id
}

Diterima : 23 Februari 2021

Disetujui : 28 Maret 2021

\begin{abstract}
Keamanan kampung adalah studi kasus yang dewasa ini menjadi perhatian dalam masyarakat madani akhir ini. Berbagia kawasan perumahan, perkampungan dan bisnis lainnya menjadikan bahasan ini sebagai salah satu komponen penting dalam lingkungan yang mereka bangun. Sudah menjadi kebutuhan yang mendasar akan keamanan dan kenyamanan lingkungan dalam tempat tinggal bagi masyarakat modern saat ini. Sudah menjadi tren berbagai kawasan menerapkan prinsip on gate system atau satu sistem pintu masuk. Dalam sistem ini memang keamanan dan ketertiban keluar masuk warga, kerabat, hingga barang dapat dipantau oleh sistem penjagaan yang ada pada gerbang. Dengan kondisi seperti ini kehadiran sebuah sistem yang otomatis akan sangat diperlukan. Hal ini merujuk pada berbagai kebiasaan yang ada pada perkampungan, seperti penerapan aturan retribusi, ijin keluar masuk, hingga otoritas kampung lainnya seperti kendaraan barang, kendaraan berat, tamu, bahkan penduduk musiman (tidak menetap). Pembuatan sistem portal yang otomatis akan membantu otomatisasi memenuhi kebutuhan tersebut. Digunakan observasi dan diskusi dengan narasumber kompeten dalam mewujudkan sistem ini. Portal dilengkapi dengan sensor ultrasonic untuk mendeteksi tinggi dan lebar kendaraan. Data yang terbaca dari sensor akan diolah dalam microcontroller yang selanjutnya akan ditampilkan pada smartphone pemegang kendali untuk bukatutup portal. Portal dapat dikendalikan dari jarak jauh dengan menggunakan koneksi internet. Portal dapat membaca jenis kendaraan yang melintas secara sederhana sesuai dengan kategori yang telah ditentukan. Sistem Portal Maya yang telah dibangun dan berfungsi dengan baik untuk membaca obyek prototipe kendaraan yang melintas.
\end{abstract}

Kata Kunci-On Gate System, Portal, Sensor Ultrasonic, Sistem Satu Gerbang,IoT

\section{PENDAHULUAN}

Dewasa ini banyak kawasan perkampungan yang mulai memasang portal kampung, yang tidak lain bertujuan untuk menjaga keamanan dan ketentraman kampung. Secara sederhana portal dijaga oleh petugas keamanan yang bertugas memeriksa dan merekam segala aktifitas keluar masuk baik kendaraan ataupun orang. Beberapa ada yang menerapkan penangguhan kartu identitas ketika melintas. Hal ini pada perkembangan teknologi dewasa ini dirasa akan sangat menggangu kecepatan mobilisasi dalam kampung tersebut. Secara garis besar portal akan bertugas membatasi segala aktifitas segala sesuatu yang melintasinya. Dalam portal ini berlaku berbagai kebijakan otoritas sesuai dengan peraturan yang disepakati dalam kampung yang harus dipatuhi oleh siapapun yang melintas. Portal Maya Kendaraan Kampung Berbasis IOT Dengan Sensor Ultrasonik yang selanjutnya disebut Portal maya merupakan rangkaian portal yang dilengkapi dengan sensor tanpa petugas penjaga dan akan terbuka dengan kendali jarak jauh yang dilakukan oleh pengurus kampung.

Portal ini didesain untuk mendeteksi tinggi kendaraan yang melintas. Dengan ketentuan tertentu definisi kendaraan yang melintas dapat dikelompokkan dengan tinggi kendaraan. Dalam kasus ini penulis membatasi pada tinggi kendaraan yang melintas dan mendefinisikannya menjadi beberapa kelompok. Dalam uji coba alat obyek melintas dibatasi pada kendaraan roda 4 lebih dan tidak diperkenankan untuk orang melintas melewati portal maya dan kendaraan melintas ditentukan melewati suatu lintasan tertentu. 


\section{TINJUAN PUSTAKA}

\section{A. Penelitian Terkait}

Penelitan pertama yang dilakukan oleh Muslimin, Ahmad Maulana dalam Sistem Pembuka Portal Dan Menyalakan Lampu Otomatis Menggunakan Sensor RFID RC522 Dan Bluetooth HC-05 Pada Perumahan Karyawan, diperoleh hasil penelitian bahwa dalam membuat sebuah portal pada wilayah perkampungan dengan akses pembuka kunci portal RFID, semua perintah membuka dipicu dari dalam RFID dengan ketentuan ada identitas pengguna yang sudah didaftarkan dalam sistem. RFID didekatkan dengan perangkat penerima dan akan meneruskan perintah untuk membuka portal. Dalam rangkaian sistem ini data pengguna akan direkam dan disimpan dalam memori RFID sehingga data pemegang masing-masing RFID dapat dipantau. RFID merupakan kunci untuk membuka portal perkampungan. Dalam sistem ini portal hanya dapat dibuka oleh RFID atau warga terdaftar terlebih dahulu [1].

Penelitian kedua yang dilakukan oleh Ben Candra S, Aris Sunawar, Nur Hanifah Y dalam Prototipe Portal Komplek Perumahan Dengan Sistem RFID (Radio frequency identification) Berbasis Arduino Mega 2560, diperoleh hasil penelitian bahwa dalam pembuatan portal pada wilayah kampung dengan akses pembuka kunci RFID, telah dapat dilakukan identifikasi data penghuni dari database kartu RFID yang telah tersimpan. Sistem akan berjalan dengan RFID yang sudah direkam agar dapat dikenali sebagai member atau anggota dari warga kampung. Dalam sistem ini portal yang tak dapat dibuka dikarenakan RFID tidak terdaftar sebagai warga, dilakukan verifikasi KTP (Kartu Tanda Penduduk) oleh petugas yang berjaga pada portal [2].

Penelitian ketiga yang dilakukan oleh Taufiq Ismail dalam Prototipe Portal Kompleks Perumahan Menggunakan Akses EKtp Dan Password Berbasis Mikrokontroller, diperoleh hasil penelitian bahwa dalam pembuatan portal kampung dimanan untuk membuka dan membuka portal diperlukan pemindaian E-Ktp. E-Ktp adalah sudah terdaftar sebagai warga perkampungan. Selain itu dapat dilakukan verifikasi tambahan dengan memasukkan password untuk membuka portal [3].

Dalam ketiga penelitian di atas sistem portal kampung yang lebih praktis dan penerapan teknologi Internet Of Things (IoT). Sistem lebih praktis tanpa menggunakan perangkat tambahan RFID seperti penelitian sebelumnya. Sistem menerapkan IoT dikarekan tanpa diperlukan instalasi kabel terhubung namun menggunakan wireless atau internet yang dikirimkan kepada perangkat notifikasi sehingga lebih simpel dalam pemasangannya.

\section{B. Arduino}

Arduino adalah kit (seperangkat) elektronik atau papan rangkaian elektronik yang open source (dapat dimodifikasi sesuai kebutuhan) yang di dalamnya terdapat komponen utama sebuah chip mikrokontroler. Mikrokontroler adalah chip atau IC (integrated circuit) yang bisa diprogram menggunakan komputer[4]. Tujuan menanamkan program pada mikrokontroler adalah agar rangkaian elektronik dapat membaca input, memproses input tersebut dan kemudian menghasilkan output sesuai yang diinginkan. Mikrokontroler bertugas sebagai otak yang dimana memegan peranan penting dalam mengendalikan input, proses dan output dari sebuah rangkaian elektronik. Mikrokontroler diprogram menggunakan bahasa pemrograman arduino yang memiliki kemiripan syntax dengan bahasa pemrograman C[5][6]. C. Sensor

Adalah perangkat yang digunakan untuk mendeteksi perubahan besaran fisik seperti tekanan, gaya, besaran listrik, cahaya, gerakan, kelembaban, suhu, kecepatan dan fenomenafenomena lingkungan lainnya. Setelah mengamati terjadinya perubahan, Input yang terdeteksi tersebut akan dikonversi mejadi Output yang dapat dimengerti oleh manusia baik melalui perangkat sensor itu sendiri ataupun ditransmisikan secara elektronik melalui jaringan untuk ditampilkan atau diolah 
menjadi informasi yang bermanfaat bagi penggunanya. Ada berbagai macam sensor yang memiliki kegunaan dan fungsi yang berbeda-beda sesuai dengan peruntukannya. Adapun dalam penelitian ini digunakan Sensor Ultrasonik atau Sensor Jarak sebagai pengindra. Sensor bekerja berdasarkan prinsip dari pantulan suatu gelombang suara, dimana sensor ini menghasilkan gelombang suara yang kemudian menangkap kembali dengan perbedaan waktu sebagai dasar pengindra[7][8].

\section{Internet Of Things (IoT)}

Secara sederhana Internet Of Things (IoT) adalah konsep komputasi tentang objek seharihari yang terhubung ke internet dan mampu mengidentifikasi diri ke perangkat lain [9]. IoT adalah konsep yang cukup sederhana, yang artinya menghubungkan semua objek fisik di kehidupan sehari-hari ke Internet. IoT terdiri atas dua bagian utama yaitu Internet yang mengatur konektivitas dan Things yang berarti objek atau perangkat. IoT mendefinisikan diri dimana konektifitas internet dapat bertukar informasi satu sama lainnya dengan bendabenda yang ada di sekelilingnya. IoT mempermudah kegiatan manusia dalam melakukan berbagai aktifitas seharihari. Semua kegiatan dapat dilakukan dengan sangat praktis dan adanya sistem kontrol karena perangkat yang terhubung menyebabkan kehidupan akan lebih efektif dan efisien yang terus akan bertambah sesuai dengan kebutuhan [10].

\section{Metodologi Penelitian}

Tahap-tahap dalam penelitian yang dilakukan oleh penulis dapat dijelaskan sebagai berikut :

1. Studi Pendahuluan

Merupakan tahap awal dalam penelitian yang bertujuan untuk mengidentifikasi masalah yang berkaitan dengan topik penelitian, sehingga dapat mengidentifikasi dan mengetahui masalah yang akan dibahas.

2. Perumusan Masalah
Adalah tahap yang bertujuan agar peneliti memahami permasalahan secara spesifik sehingga dapat lebih fokus dalam menyelesaikan masalah yang akan dibahas.

3. Menentukan Tujuan

Pada tahap ini ditentukan tujuan penelitian yaitu pembuatan alat pembatu penjagaan portal di kawasan perkampungan yang dikhususkan untuk mendeteksi kategori kendaraan yang keluar masuk perkampungan. Dengan kontrol akses buka-tutup pintu dan dapat dilakukan monitoring dari portal itu sendiri dengan kendali jarak jauh tanpa kabel.

4. Studi Literatur

Peneliti melakukan studi literatur dengan berdiskusi dengan para pakar yang kompeten, mengumpulkan, membaca, dan memahami referensi yang berasal dari jurnal penelitian, buku elektronik (e-book), datasheet komponen, dan sumber pustaka lainnya yang berkaitan dengan topik penelitian.

\section{Perancangan Desain Tampilan}

Pada tahap ini dilakukan perancangan desain sistem atau model dari alat yang akan dibuat. Desain sistem sendiri terdiri dari diagram blok sistem yang selanjutnya dikembangkan menjadi sistem keseluruhan.

6. Perancangan Sistem

Tahap ini terdiri dari perancangan perangkat keras dan perancangan perangkat lunak. Perancangan perangkat keras terdiri dari perancangan rangkaian. Perancangan perangkat lunak terdiri dari pembuatan program tampilan sistem.

\section{Pengujian Sistem}

Pada tahap dilakukan pengujian pada sistem untuk mengetahui tingkat keberhasilan alat yang telah dibuat.

\section{A. Penggunaan Sensor}

Dalam penelitian ini digunakan Sensor Ultrasonik untuk menangkap obyek yang melintas pada rangkaian alat yang terpasang sebagai portal. Sensor Ultrasonik dipasang untuk mengirimkan data ketinggian obyek yang melintas dan mengirimkan pada otak perangkat yang dalam hal ini menggunakan mikrokontroler. Data-data yang direkam ini 
akan diteruskan menuju mikrokontroler pada Arduino pada rangkaian.

\section{B. Pendefinisian Obyek}

Pembacaan ketinggian obyek yang telah dikirimkan selanjutnya akan diolah sesuai dengan pendefinisian yang telah dikaji sebelumnya. Data-data ketinggian obyek melintas ini akan disusun dan diterjemahkan menjadi sebuah definisi obyek dari nilai yang dihasilkan sensor. Pendifinisian ini dilakukan pada mikrokontroler pada Arduino dengan Bahasa Mikrokontroler.

\section{Pengiriman Notifikasi}

Pengiriman data ini adalah hasil definisi dari pengukuran jarak obyek yang telah dilakukan. Dalam proses ini pengiriman secara wireless data dilakaukan dengan konsep IoT. Dalam konsep ini data disimpan menggunakan media Firebase Google dan selanjutnya diteruskan menuju pada smartphone yang ditentukan sebagai penerima. Penerimaan data dapat berupa informasi singkat obyek yang terbaca dengan format yang sudah dirancang. Pada smartphone dapat dilakukan respon terhadap obyek yang telah lewat. Respon terhadap obyek dapat berupa perintah bukatutup portal serta informasi besaran kewajiban membayar retribusi atau iuran kampung.

\section{Gambaran Sistem}

Portal Maya Kendaraan Kampung Berbasis Iot Dengan Sensor Ultrasonik selanjutnya disebut Portal Maya merupakan sistem sebagai pengganti portal konvensional pada gerbang perkampungan, portal yang dapat dikendalikan dalam jarak jauh untuk media penghalang yang dapat dibuka-tutup ketika ada kendaraan yang lewat. Sistem merupakan instalasi terpisah yang dipasang dalam gerbang perkampungan dan media smartphone yang ada dalam pengurus atau penjaga kendali portal. Data dikirimkan dalam media non kabel yang mampu mengirimkan secara online. Sensor terbatas pada tinggi serta jarak posisi kendaraan yang melewati alat deteksi. Secara sederhana sistem dapat dijelaskan pada gambar berikut :

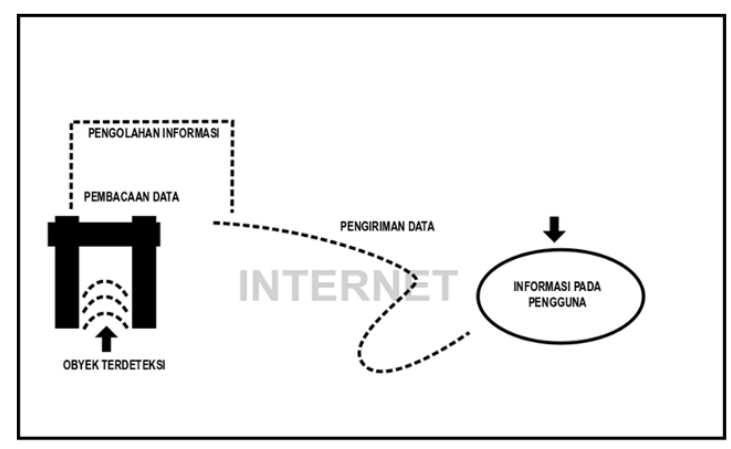

Gambar 1 Skema Alat Portal Maya

Informasi yang diterima pada pengguna berupa informasi bahwa kendaraan melintas diklasifikasikan berdasarkan ketinggian dan lebar kendaraan. Untuk setiap kelompok ukuran kendaraan akan mendapat perlakuan klasifikasi yang sudah ditetapkan sebelumnya yaitu informasi kategori dan informasi besarnya kewajiban retribusi (iuran). Dengan mekanisme ini kendaraan tidak dipersilahkan melintas sebelum ada persetujuan buka-tutup portal untuk melintas. Dalam pembacaan jarak kendaraan, akan dilakukan perhitungan ukuran kendaraan sehingga dapat didefinikan untuk kategori kendaraan. Perhitungan dilakukan dengan menentukan tinggi dan lebar kendaraan yang dibaca dari sensor, dengan lebar didapat dari hgasil perhitungan jarak sensor kanan dan kiri sistem dan untuk tinggi didapat dari jarak sensor atas sistem. Kategori kendaraan dibagi menjadi beberapa perhitungan dengan rumusan sebagai berikut :

1. Kendaraan Bus untuk dengan miniatur ukuran lebar $13 \mathrm{~cm}$ dan tinggi $18 \mathrm{~cm}$ (skala $1: 20)$.

2. Kendaraan Truck untuk dengan miniatur ukuran lebar $12 \mathrm{~cm}$ dan tinggi $16 \mathrm{~cm}$ (skala $1: 20)$.

3. Kendaraan Ambulance untuk dengan miniatur ukuran lebar $14 \mathrm{~cm}$ dan tinggi 14 cm (skala 1:20).

\section{Blok Diagram Sistem}

Dasar perancangan sistem ini adalah proses pengumpulan data dari sensor ultrasonik sebagai input yang kemudian dikirimkan pada microcontroller, selanjutnya data dari microcontroller akan dikirim kembali kepada 
perangkat sebagai output. Blok diagram dapat dijelaskan pada gambar berikut :

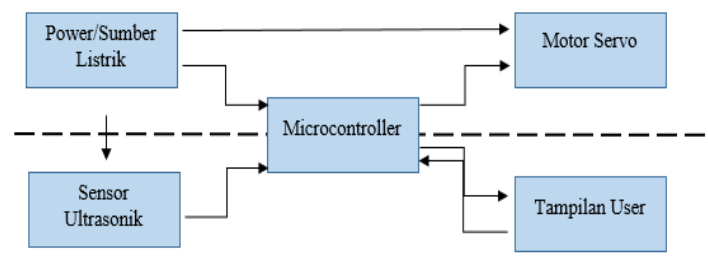

Gambar 2 Blok Diagram Portal Maya

\section{Alat, Bahan, dan Fungsi Peralatan}

Alat dan Bahan yang digunakan dalam membuat sistem Portal Maya dapat dijelaskan sebagai berikut :

1. Mikrokontroller (Microcontroller)

Berfungsi sebagai pemroses data input dan output serta sebagai media komunikasi dan pertukaran data antara sensor ultrasonik dengan Motor servo sebagai replika portal.

2. Sensor Ultrasonik

Sensor Ultrasonik adalah sensor ultrasonik HC-SR04. Sensor ini berfungsi sebagai pengirim, penerima, dan pengontrol gelombang ultrasonik. Jarak ukur dari sensor ini $2 \mathrm{~cm}-4 \mathrm{~m}$ dengan akurasi $3 \mathrm{~mm}$. Memiliki 4 pin, pin Vec untuk listrik positif, pin Gnd untuk ground-nya, pin Trigger untuk trigger keluar sinyal dari sensor, dan pin Echo untuk menangkap sinyal pantul dari benda.

3. Set Portal dengan Motor Servo

Digunakan sebagai mekanisme portal seperti portal kampung konvensional. Portal menggunakan penggerak Motor servo untuk membuka dan menutup. Portal dikendalikan dari sistem yang dipantau dari smartphone melalui tampilan user yang terkoneksi dengan sistem. Didefiniskan beberapa klasifikasi ukuran dan ketinggian kendaraan sesuai yang sudah didefinisikan untuk miniatur dengan ukuran lainnya dikategorikan sebagai uncategorize (tidak dalam kategori).

Diagram flowchart sistem dapat dijelaskan dalam gambar berikut :

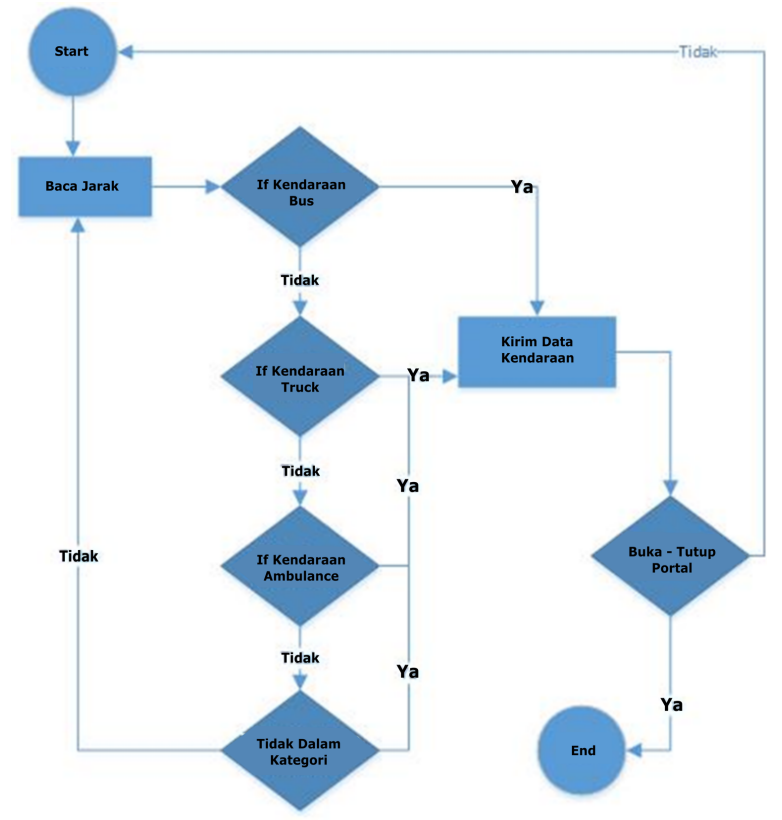

Gambar 3 Flowchart Sistem Portal Maya

Dalam perancangan perangkat lunak dilakukan dengan memprogram microcontroller dengan software Arduino IDE. Dalam perancangan desain tampilan sistem pada smartphone akan ditampilakan kategori kendaraan, besarnya nominal retribusi, dan menu bagi operator untuk membuka dan menutup pintu portal. Selain informasi kendaraan yang masuk juga disediakan tampilan ilustrasi gambar tiap kategori kendaraan. Dalam kondisi tidak ada kendaraan yang melintas, akan ditampilkan data kondisi kosong dan gambar kendaraan akan menampilkan ilustrasi gambar jika kondisi kosong. Pada menu gate adalah pilihan dimana berupa tombol yang dapat dipilih salah satu dalam hal ini tutup atau buka. Pilihan tutup untuk intruksi menutup pintu portal begitu sebaliknya pilihan buka untuk membuka pintu portal. Pada kolom disamping jenis dan tarif akan terisi secara otomatis sesuai dengan hasil pembacaan data dari obyek kendaraaan yang melintas.

\section{HASIL DAN PEMBAHASAN}

\section{B. Perancangan Sistem}

Dalam penyusunan alat, sistem disusun dari tatanan tiga buah sensor yang akan dilewati obyek dari atas, kanan, dan kiri obyek serta sebuah Motor servo yang berfungsi sebagai 
penggerak portal penghalang yang dapat membuka dan menutup sesuai dengan instruksi sistem. Sistem menggunakan tiga sensor yang akan membaca secara bersamaan obyek yang melintas dengan patokan ukuran yang sudah ditentukan untuk mengidentifikasi klasifikasi kendaraan yang sudah ditentukan. Hasil dari pembacaan sensor akan diteruskan dalam microcontroller untuk diteruskan menjadi output pada device smartphone melalui wifi (wireless) dan ltrason pada Motor servo yang bertugas sebagai portal untuk buka-tutup lintasan.

Dalam sistem yang dibangun, hasil dari pembacaan semua sensor dipadukan untuk dirumuskan ukuran dari obyek yang terbaca tersebut. Sensor 1trasonic memiliki standar jarak pengukuran maksimal yang terbaca sejauh 4 meter. Sistem untuk prototipe dalam penerapan yang lebih besar.

\section{B. Pembuatan Sistem}

Dalam pembuatan sistem dirangkai microcontroller dan Sensor Ultrasonik sesuai dengan desain sistem yang diaplikasikan pada media set portal yang dibuat sedemikian rupa. Penataan Sensor Ultrasonik sebanyak 3 unit untuk membaca jarak dari samping kanan dan kiri obyek serta dari posisi atas obyek dengan jarak simulasi obyek kendaraan yang melintas. Rangkaian portal dengan Motor servo ditata terhubung dengan set portal sebagai simulasi portal yang akan dilewati kendaraan. Penataan sistem secara visual dapat digambarakan pada gambar berikut :

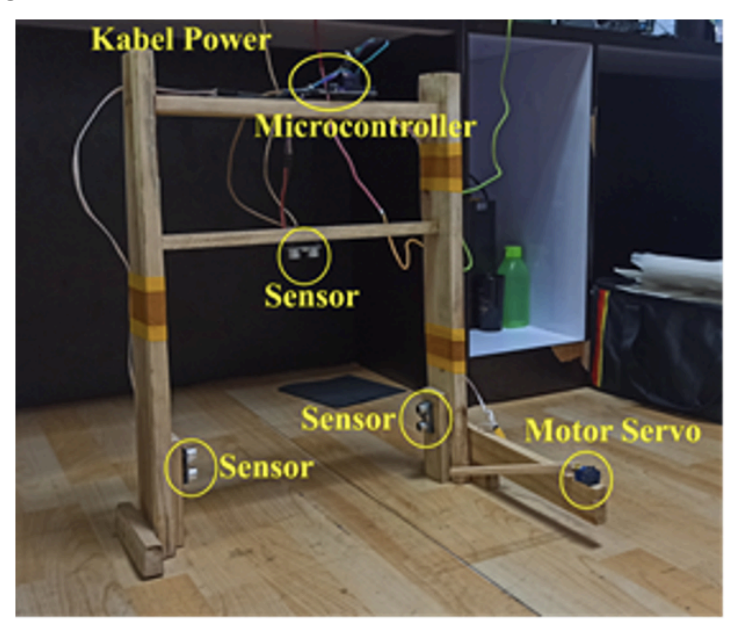

Gambar 5 Pembangunan Sistem
Ketiga sensor akan membaca obyek secara bersamaan dan mengirimkan data terbaca kedalam microcontroller. Data dalam microcontroller diolah sesuai dengan program yang dirancang dan mengirimkan hasil olah data kepada smartphone, yang selanjutnya dalam smartphone dapat dilakukan kendali untuk buka-tutup portal. Data yang telah diolah dalam microcontroller dikirimkan dengan prinsip IoT yaitu melalui internet. Sistem berjalan dengan koneksi internet dan sumber daya. Dalam penerapan sistem, data yang sudah terproses dikirimkan dengan bantuan penyimpanan data tersebut di database Firebase Google, yang selanjutnya akan dikirim ke smartphone. Smartphone menerima data hasil olahan dan menampilkan dalam interface pengguna. Firebase Google membantu untuk menyimpan data hasil olah guna efisiensi proses yang ada pada microcontroller. Secara sederhana detil proses IoT dalam sistem dapat dijelaskan pada gambar 6.

Dalam sistem dilakukan logika untuk membedakan obyek kendaraan sehingga obyek yang terbaca dapat dibagi menjadi definisi yang sudah diskenariokan. Beserta pengolahan data lainnya seperti tarif dan ilustrasi gambar yang akan dimunculkan sebagai tanda untuk memperjelas obyek kendaraan yang terbaca dalam portal. Code untuk pembacaan sensor seperti pada gambar 7 .

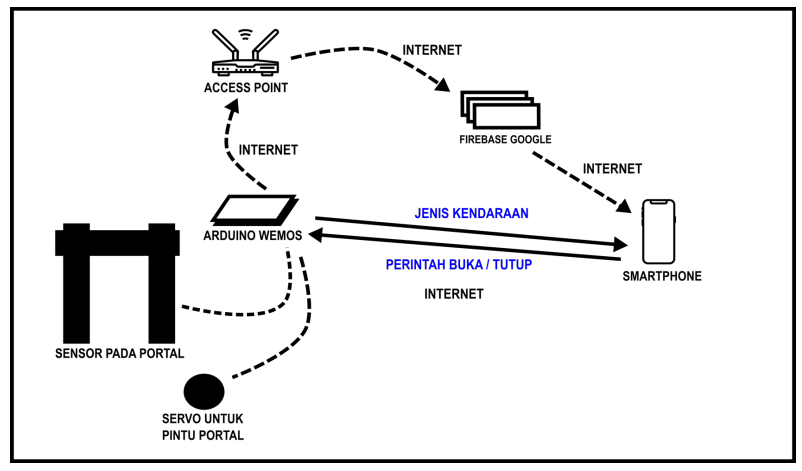

Gambar 6 Penggunaan IoT Pada Sistem 


\section{Jurnal Sistem Komputer dan Kecerdasan Buatan Vol. IV No. 2 Tahun 2021}

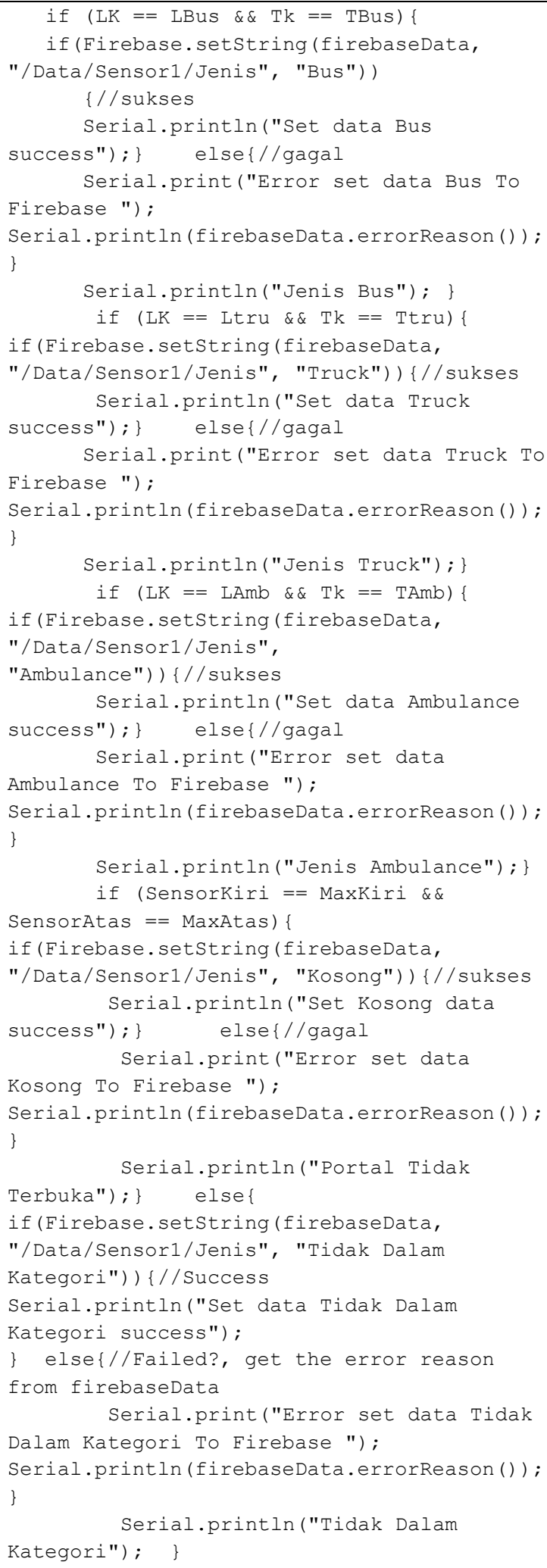

Gambar 7 Pseudo Code Microcontroller

Data yang sudah diolah akan disimpan di database Firebase Google, yang selanjutnya akan dikirim ke smartphone. Smartphone menerima data hasil olahan dan menampilkan dalam interface pengguna. Dalam membuat interface pengguna dipergunakan bahasa .java. Code untuk interface (tampilan) pada pengguna seperti pada gambar berikut :

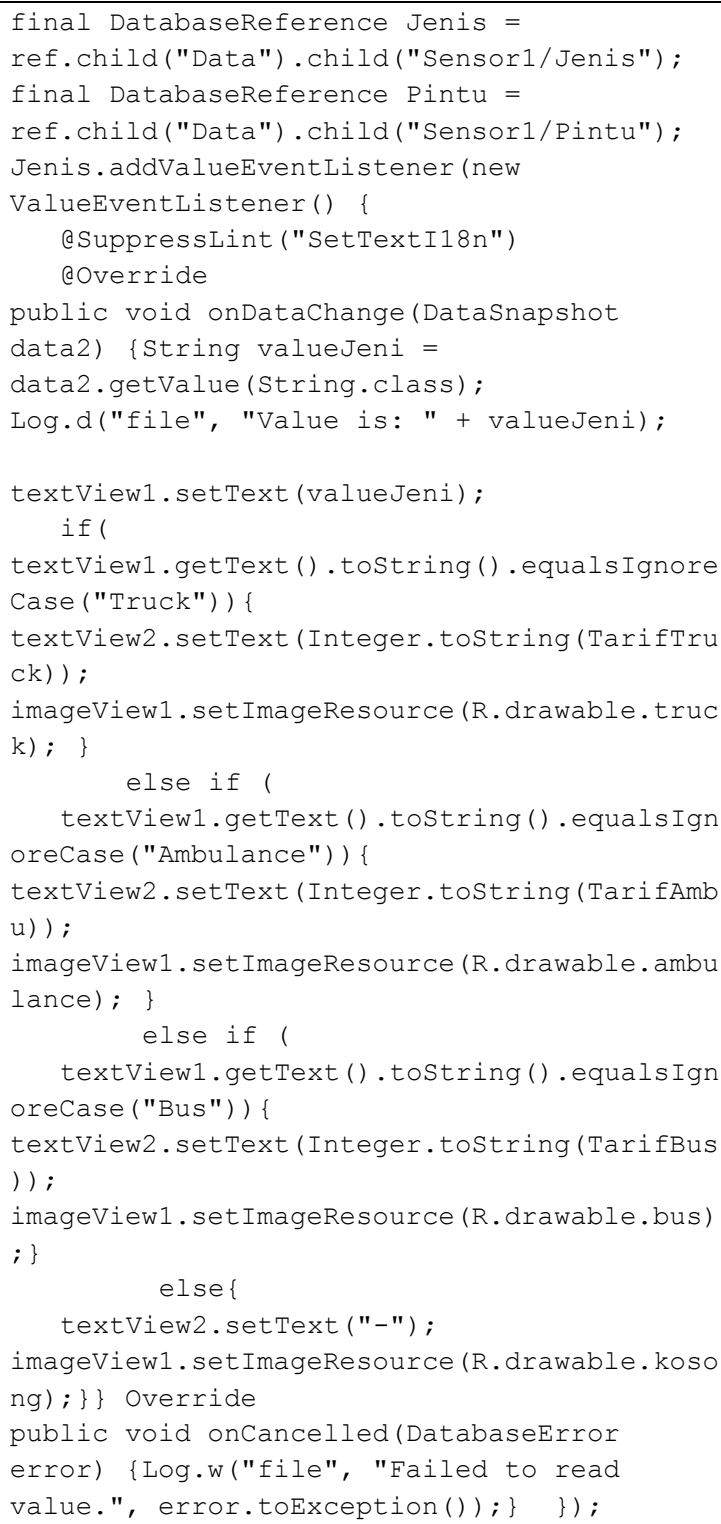

Gambar 8 Pseudo Code Tampilan Pengguna

Dalam settingan Motor servo dilakukan sinkronisasi antara tampilan yang menampilkan pilihan menu buka dan tutup dengan Code pada microncontroller untuk menjalankan perintah pada Motor servo. Berikut Code untuk mekanisme buka tutup pada Motor servo sebagai simulasi pintu portal :

//microcontroller

if (Firebase.getString (firebaseData, "/Data/Sensor1/Pintu")) $\{/ /$ Jika Success

String Status =

(firebaseData.stringData()) ; if (Status $==$ "ON") \{ 


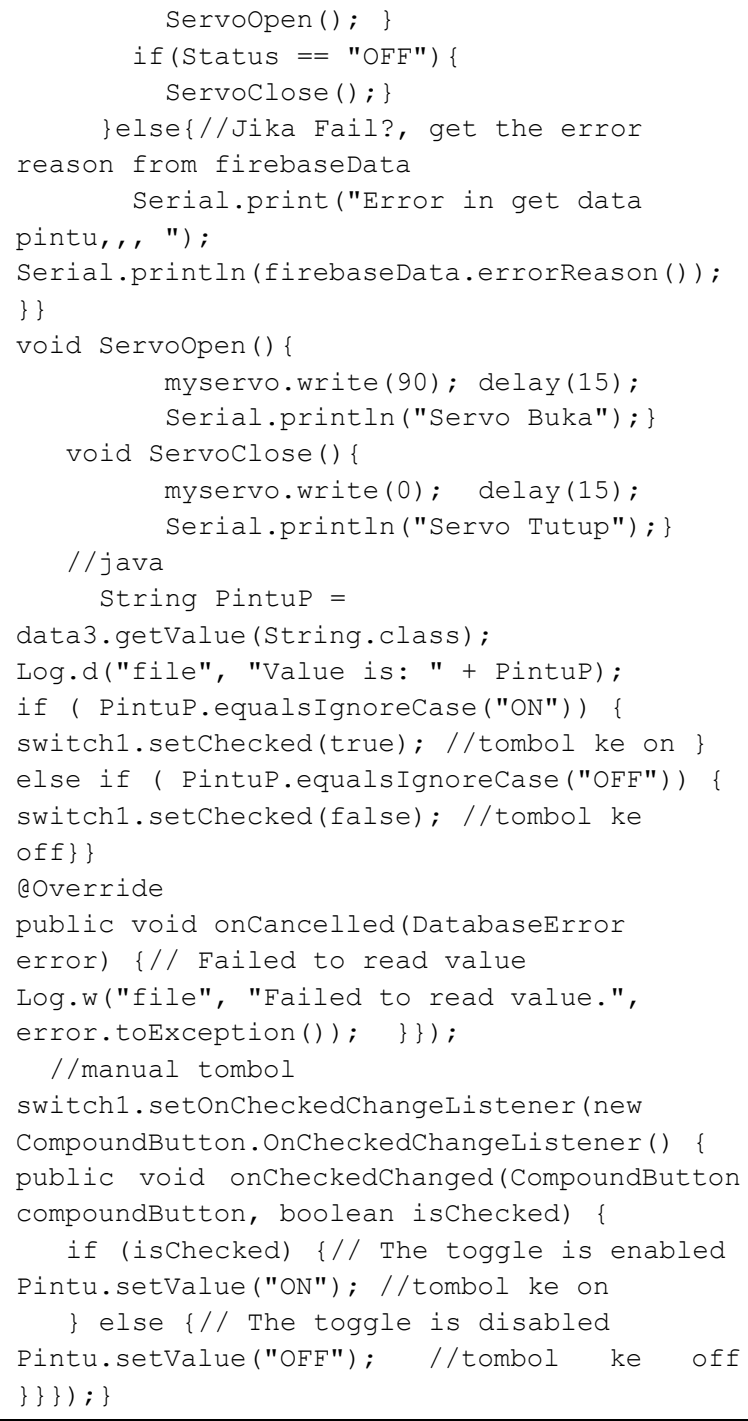

Gambar 10 Pseudo Code Integrasi Pengguna

\section{Pengujian Sistem}

\section{Pengujian Pertama}

Dilakukan dengan simulasi kendaraan Bus melintasi portal dan dilakukan simulasi perintah pintu portal dibuka.

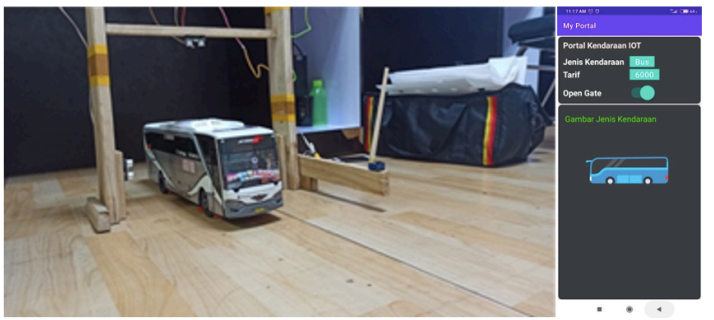

Gambar 11 Uji Kategori Bus Portal Terbuka

\section{Pengujian Kedua}

Dilakukan dengan simulasi kendaraan Truk melintasi portal dan dilakukan simulasi perintah pintu portal ditutup.

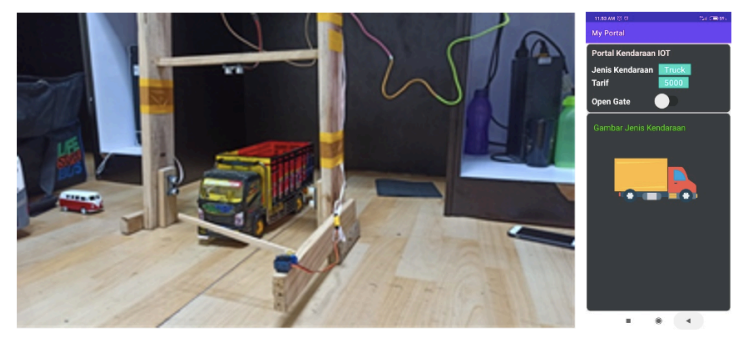

Gambar 12 Uji Kategori Truk Portal Tertutup

\section{Pengujian Ketiga}

Dilakukan dengan simulasi kendaraan Ambulan melintasi portal dan dilakukan simulasi perintah pintu portal dibuka.

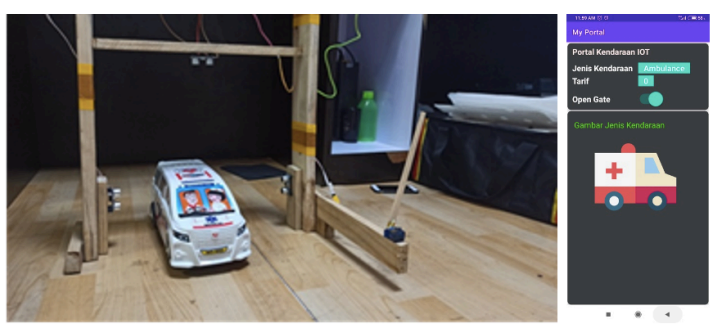

Gambar 13 Uji Kategori Ambulan Portal Terbuka

\section{Pengujian Keempat}

Dilakukan dengan simulasi kendaraan Kategori lainnya melintasi portal dan dilakukan simulasi perintah pintu portal ditutup.
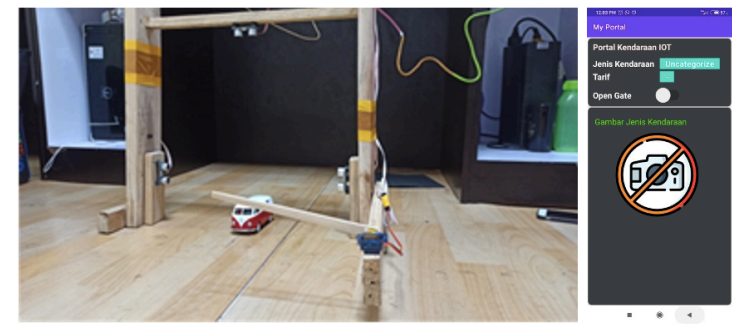

Gambar 14 Uji Bukan Kategori Portal Tertutup

Dokumentasi hasil pengujian sebagai berikut :

Tabel 1 Tabel Pengujian

\begin{tabular}{|l|l|l|l|}
\hline Durasi Uji & \multicolumn{1}{|c|}{ Hasil } & Portal & \multicolumn{1}{c|}{ Ket. } \\
\hline 1 Menit & Bus & Buka & Benar \\
\hline 1 Menit & Truck & Tutup & Benar \\
\hline 1 Menit & Ambulance & Buka & Benar \\
\hline 1 Menit & Uncategorize & Tutup & Benar \\
\hline
\end{tabular}

Dari pengujian yang dilakukan didapatkan beberapa hasil sebagai berikut :

1. Akurasi sistem yang telah dibangun adalah dapat mengenali obyek dengan benar 
2. Sistem dapat mengenali obyek dibuktikan dengan output (hasil) dari pembacaan sensor yang terkirim kepada smartphone yang disinkronkan dalam sistem. Sistem dapat membedakan obyek sesuai dengan skenario yang telah dibuat dan dapat memberi keputusan (untuk membuka dan menutup portal dari motor servo) sesuai dengan skenario yang telah dibuat.

\section{KESIMPULAN}

Secara umum penulis menyimpulkan bahwa sistem Portal Maya yang telah dibangun dan berfungsi dengan baik untuk membaca obyek prototipe kendaraan yang melintas. Portal Maya dapat membaca jenis kendaraan yang melintas secara sederhana sesuai dengan kategori yang telah ditentukan, hal ini didapat dari hasil pembacaan ukuran dan pengolahan data dari hasil pembacaan sensor ultrasonik.

\section{DAFTAR PUSTAKA}

[1] Muslimin, Ahmad Maulana. 2019. Sistem Pembuka Portal Dan Menyalakan Lampu Otomatis Menggunakan Sensor Rfid Rc522 Dan Bluetooth Hc-05 Pada Perumahan Karyawan. Prosiding Seminar Nasional Teknologi V.

[2] Candra Ben, Aris Sunawar Dan Nur Hanifah Y. 2016. Prototipe Portal Komplek Perumahan Dengan Sistem Rfid (Radio Frequency Identification) Berbasis Arduino Mega 2560. Vol 1 No 2 (2016) : Jurnal Of Electrical Vocational Education And Technology.

[3] Taufiq Ismail. 2018. Prototipe Portal Kompleks Perumahan Menggunakan Akses E-Ktp Dan Password Berbasis Mikrokontroller.

[4] Kadir, Abdul. (2013). Panduan Praktis Mempelajari Aplikasi Mikrokontroler Dan Pemrogramannya Menggunakan Arduino. Yogyakarta: Andi Offset.

[5] Susilo, Eko Kunto Dkk. 2019. Iot-Based Intelligent Green Houses (Igh) Using LoRa Technology. International Journal Of
Innovation, Creativity And Change. Volume 9.

[6] Susilo, Eko Kunto Dkk. 2019. Lo-Ra Based Framework For Smart Green House Monitoring Systems. International Journal Of Innovation, Creativity And Change. Volume 9.

[7] F. Musthofa, And H. Winarno. 2015. "Sistem Deselerasi Kecepatan Otomatis Pada Mobil Berdasarkan Jarak Menggunakan Sensor Ultrasonik Hc-Sr04 Berbasis Arduino Mega 2560," Gema Teknologi, Vol. 18, No. 3, Pp. 110-116, Oct.

[8] Puspasari Fitri. 2019. Sensor Ultrasonik Hcsr04 Berbasis Arduino Due Untuk Sistem Monitoring Ketinggian. Jurnal Fisika Dan Aplikasinya Volume 15, Nomor 2, 2019.

[9] Burange, Anup \& Misalkar, Harshal. (2015). Review Of Internet Of Things In Development Of Smart Cities With Data Management \& Privacy. 189-195. 10.1109/Icacea.2015.7164693.

[10] L. Yang, Y. Qi, J. Han, C. Wang And Y. Liu, "Shelving Interference And Joint Identification In Large-Scale Rfid Systems," In Ieee Transactions On Parallel And Distributed Systems, Vol. 26, No. 11, Pp. 3149-3159, 1 Nov. 2015, Doi: 10.1109/Tpds.2013.276. 